\title{
Isolation and molecular characterization of genotype 1 Japanese encephalitis virus, SX09S-01, from pigs in China
}

\author{
Qi S Cao ${ }^{1}$, Xiang M Li ${ }^{1,2^{*}}$, Qiao Y Zhu', Dan D Wang ${ }^{1}$, Huan C Chen ${ }^{1,2}$ and Ping Qian ${ }^{1,2^{*}}$
}

\begin{abstract}
Background: Pigs play a critical role in Japanese encephalitis virus (JEV) transmission between mosquitos and humans. In 2009, lots of piglets developed symptom of viral encephalitis in a pig farm in Yunchen, Shanxi province.

Methods: Virus isolation was carried out in BHK-21 cells. Immunohistochemistry, RT-PCR and indirect immunofluorescent assay were used to identify the newly isolated virus. The complete genome of one isolate (SX09S-01 strain) was sequenced and analyzed. Two phylogenetic trees were constructed on the basis of the 24 full-length JEV genomes and $62 \mathrm{E}$ genes mostly selected from China.

Results: JEV SX09S-01 strain was isolated from piglets. Sequence analysis indicates that the completed genome sequences of this strain consists of 10965 nucleotides and there are 13 nucleotides deletion in the 3' nontranslated variable region. Compared with other JEV strains, homology ranges from 99.1\% (XJ69) to 74.1\% (XZ0934) and 99.6\% (XJ69) to 91.1\% (XZ0934) on the level of nucleotide and amino acid sequences, respectively. Phylogenetic trees show that SX09S-01 strain belongs to genotype I and it is most closely related to the XJ69 strain.
\end{abstract}

Conclusions: Genotype I of JEV still circulates in Yuncheng and it is thus important for active surveillance on genotype I of JEV from the swine population.

\section{Background}

Japanese encephalitis (JE) is mostly prevalent in eastern and southern Asia, such as China, India and Japan [1,2]. JE has extended its geographic regions and it has been recently reported in Australia and USA [2,3]. There are approximately 30,000-50,000 JE cases and up to 10,00015,000 deaths occur worldwide each year [2,4]. In fact, the actual number of cases caused by Japanese encephalitis virus (JEV) is most likely to be much higher, and up to 175,000 each year [5]. Most of cases occurred in the young children and older people. Approximately $25 \%-30 \%$ of cases caused by JEV are fatal, and $50 \%$ result in permanent neuropsychiatric sequelae $[2,6]$.

In China, JE is one of the most important viral encephalitis and has been reported in most provinces of mainland China, except for Xinjiang Uygur Autonomous Region

\footnotetext{
* Correspondence: lixiangmin@mail.hzau.edu.cn; qianp@mail.hzau.edu.cn ${ }^{1}$ State Key Laboratory of Agricultural Microbiology, Huazhong Agricultural University, Wuhan city 430070, Hubei Province, P. R. China Full list of author information is available at the end of the article
}

and Qinhai Province [6,7]. There are still 8,000-10,000 cases reported annually and nearly $80 \%$ of globally reported cases occur in China although JE vaccines are widely used [8]. Particularly, in August 2006, an outbreak of JE occurred in Yuncheng, Shanxi Province, China Sixtysix human cases were reported with 19 fatalities [9].

JEV, the etiological agent of JE, belongs to a mosquitoborne Flavivirus within the family Flaviviridae [10]. JEV exists in a zoonotic transmission cycle between animals/ water birds and human by Culex mosquitoes, and humans are a dead-end host [11]. The viral genome is a single-stranded positive sense RNA molecule approximately $11 \mathrm{~kb}$ in length and contains a single long open reading frame (ORF) that encodes a polyprotein flanked by 5 ' and 3' nontranslated regions (NTRs). The polyprotein consists of three structural proteins, designated capsid protein $(C)$, membrane $(M$, a mature form of its precursor protein prM), and envelope protein (E), as well as seven nonstructural proteins (NS1, NS2A, NS2B, NS3, NS4A, NS4B and NS5). The prM and E proteins play

\section{Biomed Central}

(c) 2011 Shu et al; licensee BioMed Central Ltd. This is an Open Access article distributed under the terms of the Creative Commons Attribution License (http://creativecommons.org/licenses/by/2.0), which permits unrestricted use, distribution, and reproduction in any medium, provided the original work is properly cited. 
critical roles in several biological activities, such as hemagglutination, neutralization, viral binding to cellular receptors and membrane fusion. In addition, the E protein has a major role in determining the neuorovirulence or neuroinvasiveness. Phylogenetic analyses mainly focused on partial sequences derived from either the $\mathrm{C} /$ prM or $\mathrm{E}$ gene and JEV can be divided into five genotypes (GI-GV) based on the nucleotide sequence of $\mathrm{E}$ gene $[1,7,12]$.

Swine is an important reservoir and overwintering host for JEV and thus plays a critical role in the human encephalitis epidemics. However, the detailed information on JEV from pigs was lacking. Here, we report the isolation of a GI JEV from piglets that developed viral encephalitis in Yuncheng in July 2009 and this virus is designated SX09S01 strain. To investigate its molecular characters, the completed genome was sequenced and analyzed. Eight critical amino acids in the $\mathrm{E}$ protein were found to be closely related to the JEV neurovirulence. Phyogenetic trees were constructed on the basis of the 24 full-length JEV genomes and 62 completed $\mathrm{E}$ genes mostly selected from China. Phyogenetic analysis indicated that SX09S-01 strain was most closely related to the XJ69 strain.

\section{Materials and methods}

\section{Collection of samples and virus isolation}

Seven swine brain samples were collected from piglets which were suspected to be infected with JEV in Yuncheng, Shanxi province 2009. A part of brains was fixed with $4 \%$ paraformaldehyde for immunohistochemistry and others were ground and used for virus isolation.

The virus was isolated on BHK-21 cells as previous described [13]. Briefly, the supernatant was inoculated onto the monolayer of BHK-21 cells, and the cytopathic effects (CPE) was observed daily under a microscope. Culture supernatants were harvested and re-inoculated onto fresh BHK-21 cells until the typical CPE of JEV appeared. One virus was isolated and designated SX09S-01 strain.

The SX09S-01 strain was further identified by indirect immunofluorescent assay (IFA). SX09S-01 was inoculated on BHK-21 cells monolayer, and IFA was carried out 36 hours later as previously described [14]. The primary antibody is murine monoclonal antibody against JEV E protein and the secondary antibody is FITC conjugated antimouse IgG (Cat no: BA1101, Boster).

\section{Virus purification}

The SX09S-01 strain was propagated by injection into the brains of suckling mice [15]. The brain tissue was collected and ground while the first signs of paralysis emerged. The sample was centrifuged at $10000 \mathrm{r} / \mathrm{min}$ for $30 \mathrm{~min}$ and the supernatant was stored at $-80^{\circ} \mathrm{C}$ as a virus stock. Mice were bought from Center for Animal Disease Control, Hubei province and all experiments were conducted with approval of the Animal Committee of Huazhong Agricultural University.

\section{Viral RNA extraction}

Total viral RNA was extracted from the supernatant of infected cells with TRIZOL ${ }^{\circledR}$ Reagent (Invitrogen, USA) according to the manufacturer's protocol. Briefly, $200 \mu \mathrm{l}$ of sample was mixed with $1.0 \mathrm{ml}$ of TRIZOL ${ }^{\circledR}$ reagent and $0.2 \mathrm{ml}$ of chloroform. After incubation on ice for $10 \mathrm{~min}$, the aqua phase was separated by centrifugation $(12,000 \times$ $\mathrm{g}$ for $15 \mathrm{~min}$ ) at room temperature (RT) and $500 \mu \mathrm{l}$ of isopropyl alcohol was mixed with $80 \%$ of the aqua phase in a fresh tube. After incubation at RT for $10 \mathrm{~min}$, the RNA was precipitated at $12,000 \times \mathrm{g}$ at RT for $10 \mathrm{~min}$. After washing once with $80 \%$ ethanol, the pellet was briefly dried at RT and then dissolved with DEPC treated water and stored at $-80^{\circ} \mathrm{C}$ until use.

\section{Full-length genome sequence analysis of the SX09S-01 strain}

Extracted viral RNA was used as a template for cDNA synthesis using avian myeloblastosis virus (AMV) reverse transcriptase (Toyobo, Japan). The cDNA was subsequently used for PCR amplification with LA PCR ${ }^{\mathrm{TM}}$ Kit Ver.2.1 (TaKaRa, Dalian). In order to amplify the completed genome, the six pairs of primers (Table 1) were designed according to the XJ69 strain genome sequences. The PCR products were purified by agarose gels electrophoresis and then ligated directly into TA cloning vector system (Promega, USA) and sequenced. Analysis of nucleotide and deduced amino acid sequence identifies was performed by DNASTAR software.

\section{Multiple alignments and phylogenetic analysis}

The JEV strains used in multiple sequence alignments and phylogenetic analyses in this study are listed in additional file 1. Multiple sequence alignments and phylogenetic analysis were performed by the neighbor-joining (NJ) method using the Maga4.1 software. To generate the rooted trees, the Murray Valley encephalitis virus (MVE-1-51) was used as an outgroup in phylogenetic analysis.

\section{Results}

\section{Viral isolation}

In July 2009, lots of piglets developed the viral encephalitis and died in Yuncheng, Shanxi province, China. Brain samples were collected and haemorrhage lesions were found (Figure 1A). To investigate whether it was caused by JEV, specific IHC and RT-PCR were performed. IHC revealed brown positive cells in the brain (Figure 1B) and RT-PCR with the $\mathrm{C} / \mathrm{prM}$ primers resulted in the amplification of a 674 bp band (Figure 1C).

In order to isolate the pathogen, brain samples were ground and the supernatant was inoculated onto the 
Table 1 Primers used in this study for amplification of the full-length genome of SX09S-01 strain

\begin{tabular}{|c|c|c|c|c|c|}
\hline Segments & Primers & Oligonucleotide sequence $\left(5^{\prime}-3^{\prime}\right)$ & Position $^{a}$ & Length (bp) & Annealing temperature $\left({ }^{\circ} \mathrm{C}\right)$ \\
\hline \multirow[t]{2}{*}{ S1 } & $\mathrm{P} 1 \mathrm{~S}^{\mathrm{b}}$ & 5'- AGAAGTTTATCTGTGTGGACTTC-3' & $1-23$ & 1795 & 58 \\
\hline & $P 1 R^{c}$ & $5^{\prime}-$ CCACCACGATGGCTCCTGC-3' & 1777-1795 & & \\
\hline \multirow[t]{2}{*}{ S2 } & P2S & 5'- TGYTGGTCGCTCCGGCTTA-3' & $956-974$ & 1582 & 57 \\
\hline & $P 2 R$ & $5^{\prime}-$ AAGATGCCACTTCCACAYCTC - -3' & $2517-2537$ & & \\
\hline \multirow[t]{2}{*}{ S3 } & P3S & 5'- GACACTGGATGTGCCATTG-3' & 2479-2497 & 2310 & 57 \\
\hline & P3R & 5'-TCTITTGTTGTTITAAAG—3' & 4589-4608 & & \\
\hline \multirow[t]{2}{*}{ S4 } & P4S & $5^{\prime}-$ GTTGGACGACGACGGCGACTTTC-3' & $4449-4471$ & 2648 & 58 \\
\hline & P4R & 5'- AGGTGATTAGGTGCTTCAGGAGAGG-3' & 7072-7096 & & \\
\hline \multirow[t]{2}{*}{ S5 } & P5S & $5^{\prime}-$ GGTCGGAGTGGTGGCAGCAAATG-3' & 6894-6916 & 2200 & 58 \\
\hline & P5R & 5'- CCCTITAGCCTITCCGAACTCTCCG-3' & 9069-9093 & & \\
\hline \multirow[t]{2}{*}{ S6 } & P6S & $5^{\prime}-$ AGGAGTCAAGGAAGTGCTCAACG-3' & 8787-8809 & 2178 & 58 \\
\hline & P6R & $5^{\prime}-$ AGATCCTGTGTTCTTCCTCACCACC -3' & 10940-10964 & & \\
\hline
\end{tabular}

${ }^{a}$ Numbers indicate the location of the nucleotide sequence of XJ69

${ }^{\mathrm{b}} \mathrm{S}$ represents the sense primer.

${ }^{c} \mathrm{R}$ represents the anti-sense primer

fresh BHK-21 cells. BHK-21 cells appeared rounding, shrinkage and dislodgment from the cell surface under a microscope on days 3-4 after inoculation, and typical cytopathic effect (CPE) of JEV was observed (Figure 1E). Cells infected by the isolate reacted with the specific monoclonal antibody against JEV E protein by IFA. Several focuses of bright fluorescence were observed in the cytoplasm compared with normal control cells (Figure $1 G)$.

Full-length nucleotide and deduced amino acid sequence analysis

To further investigate the molecular characters of the SX09S-01 strain, the completed genome RNA was amplified with several pairs of primers listed in Table 1. It contains 10965 nucleotides in length and encoded a 10299-nucleotide single ORF (3432 amino acid residues) flanked by a 96-nucleotide 5'-NTR and a 570-nucleotide 3'-NTR. The complete genomic sequence of SX09S-01 strain was compared with other $24 \mathrm{JEV}$ strains available in GenBank (Additional file 1, indicated by boldface type). The results of multiple alignments showed that homology ranged from 99.1 (XJ69) to 74.1\% (XZ0934), and 99.6 (XJ69) to 91.41 (XZ0934) on the levels of nucleotide and amino acid, respectively. The SX09S-01 strain shares the highest nucleotide sequence homology with other strains of the GI with 97.8\% (KV1899)-99.1\% (XJ69), and amino acid sequence homology between 98.3\% (KV1899)-99.6\% (XJ69). There is further distance with the XZ0934 strain of the GV, 75.8\% and 91.4\% homology on the level of nucleotide and amino acid, respectively (Additional file 2).

NTRs might play a vital role on the biological properties, including viral replication and neurovirulence. No nucleotide changes were found when compared with other three GI strains of JEV. However, there is an additional adenine (A) nucleotide insertion comparison with other genotype strains (data not shown). The nucleotide sequences of the 3'-NTRs of SX09S-01 strain was compared with those of other 24 strains belonging to GI to GV(Figure 2). A 13nucleotide deletion immediately downstream of the translation stop codon was conserved among the 3'-NTR of the G I strains, including SX09S-01, the newly isolated strain. But a deletion of 11 nucleotides was observed in the FU strain of the GII. There was no nucleotide deletion found in 3'-NTRs of the JEV GIII strains, except for the Ling strain (25 nucleotides deletion). In addition, the 3'-NTRs of the JEV GVis about 14 nucleotides longer in than GII. The roles of these deletions in the 3'-NTR of the SX09S01 strain needs further investigation.

\section{Analysis of the E gene amino acid sequences of SX09S-01 strains}

JEV E protein is one of the major structural proteins and is closely related to viral virulence, host tropism and antigenicity. Eight amino acid residues of $\mathrm{E}$ protein play a critical role in the neurovirulence [16]. To analyze these key amino acids, we compared the $E$ protein of SX09S-01 strain with SA14-14-2, an attenuated vaccine strain, and other virulent strains. No differences among the eight key amino acid residues were found between SX09S-01 and other virulent strains (Table 2). So, we predicted that the SX09S-01 strain possessed some typical characteristics of strong virulent JEV.

\section{Phylogenetic analyses}

For better understanding of the genetic relationships and evolution of JEV strains, especially isolated in China, a total of the 62 sequenced JEV strains (shown in additional file 1) were used to construct phylogenetic trees. The genetic relationship was established on sequences of the full-length genome and the E gene sequences. 


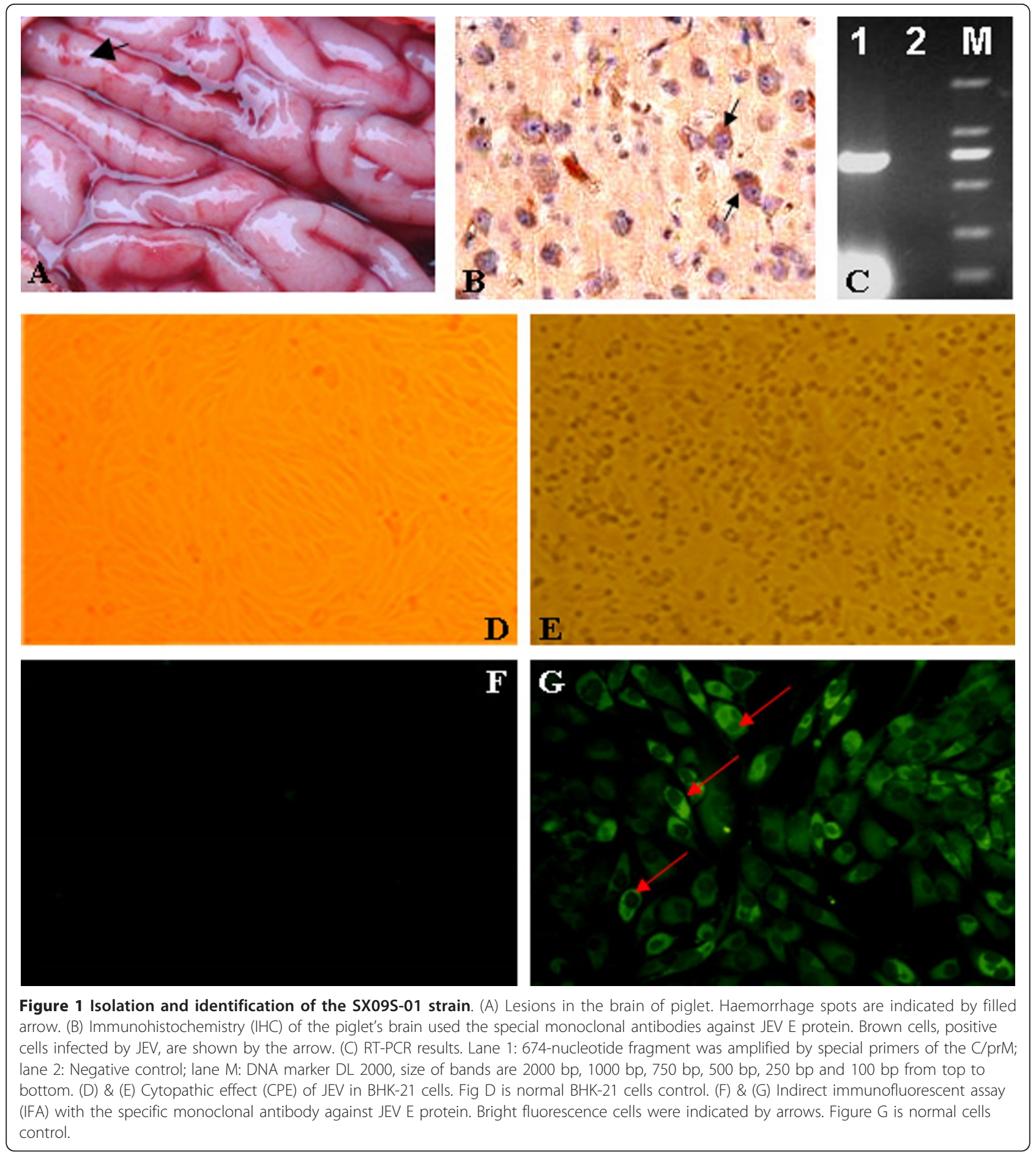

Phylogenetic tree was produced according to the fulllength sequences by the NJ method. As shown in Figure 3, all the viruses could be classified into five groups and there were two distinct phylogenetic clusters. Newly isolated SX09S-01 is classified as JEV GI and this cluster also included the XJ69 (China), Ishikawa (Japan, 1994), and KV1899 (Korea, 1999) strains. SX09S-01 was closely related to the XJ69 strain isolated from Culex tritaeniorhynchus in China. The strains from India, China, Taiwan and Japan belonged to JEV GIII and be branched into four minor clades. The first clade consisted of early isolates from China (Beijing-1), Taiwan (Ling), India (VelloreP20778) and Japan (Nakayama); The second contained the virulent strain (P3) and JaGAr-01 (Japan); The third 


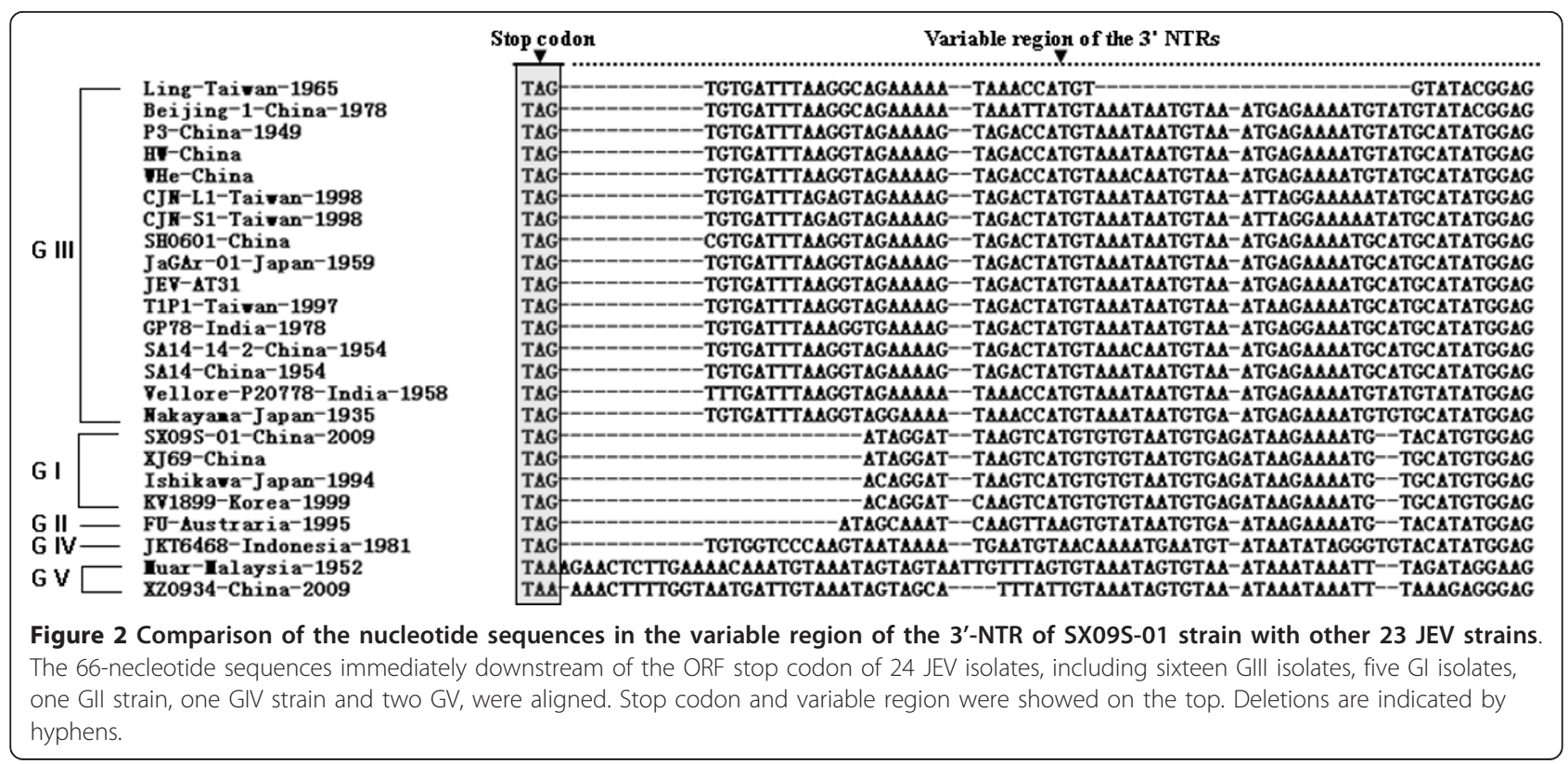

included two strains from Taiwan (CJN-L1 and CJN-S1); other strains from India and China-including SA14 and its vaccine derivatives made up the fourth clade. Strain FU (Austraria, 1995) and JKT6468 (Indonesia, 1981) belonged the GII and GIV, respectively. GV consisted of two stains, Muar strain isolated from Malaysia in 1952 and XZ0934 strain recently isolated from China in 2009.

To determine the genetic relationships of JEV, the fulllength $\mathrm{E}$ genes sequence was utilized to construct the phylogenetic tree. On the basis of the E gene sequences, a total of 62 JEV strains, which included 52 strains from China Mainland and Taiwan and 10 strains from other countries, were analyzed (Figure 4). Five distinct phylogenetic groupings were identified that corresponded to the five genotypes (GI to GV). The JEV strains isolated from China include GI, GIII and GV with the majority belonging to GI and GIII groups.

\section{Discussion}

JE is mostly prevalent in China and there are many human JE cases reported recently $[7,9,17]$. However, there is very limited information on JEV strains originated from pigs. Pigs play a critical role to JEV transmission between mosquitos and humans, it is very important to surveillance the JE in the swine population in China.

In 2009, lots of piglets developed viral encephalitis in one pig farm in Yunchen, Shanxi province, where human JE cases broke out in 2006 [9]. In this study, we isolated a new JEV stain by serial passages on BHK-21 cells in Yunchen (Figure 1). The newly isolated JEV, designated SX09S-01, belongs to genotype I by C/prM sequences analysis. Tang [18] and Nerome [19] analyzed the molecular characterizations of JEV isolates from swine in Japan. To our knowledge, it's reported that only HEN0701 and SXBJ07 strains have been isolated from swine and belong to the GI JEV in China [20,21]. In this study, we clearly confirmed that GI JEV strains still circulate in Yuncheng. It suggests that we need to pay more attentions on the prevention and treatment of swine JE in order to control human JE effectively in this region.

To fully characterize the JEV SX09S-01 strain, its complete nucleotide and deduced amino acid sequences were determined. Compared with other strains isolated from

Table 2 Comparison of eight critical amino acids closely related to the neurovirulence of JEV in E protein between the virulent strains and the attenuated vaccine strain (SA14-14-2)

\begin{tabular}{|c|c|c|c|c|c|c|c|c|}
\hline Strain & E107 & E138 & E176 & E177 & E264 & E279 & E315 & E439 \\
\hline SX09S-01 & Leu (L) & Glu (E) & Ile (I) & Thr $(T)$ & $\mathrm{Gln}(\mathrm{Q})$ & Lys (K) & Ala (A) & Lys (K) \\
\hline XJ69 & Leu (L) & Glu (E) & Ile (I) & Thr $(T)$ & $G \ln (Q)$ & Lys (K) & Ala (A) & Lys (K) \\
\hline P3 & Leu (L) & Glu (E) & Ile (I) & $\operatorname{Thr}(\mathrm{T})$ & $\mathrm{Gln}(\mathrm{Q})$ & Lys (K) & Ala (A) & Lys (K) \\
\hline HW & Leu (L) & Glu (E) & Ile (I) & $\operatorname{Thr}(\mathrm{T})$ & $\mathrm{Gln}(\mathrm{Q})$ & Lys (K) & Ala (A) & Lys (K) \\
\hline SA14 & Leu (L) & Glu (E) & Ile (I) & Thr $(T)$ & $\mathrm{Gln}(\mathrm{Q})$ & Lys (K) & Ala (A) & Lys (K) \\
\hline SA14-14-2 & Phe (F) & Lys (K) & Val (V) & Ala (A) & $\mathrm{His}(\mathrm{H})$ & Met (M) & Val (V) & $\operatorname{Arg}(\mathrm{R})$ \\
\hline
\end{tabular}




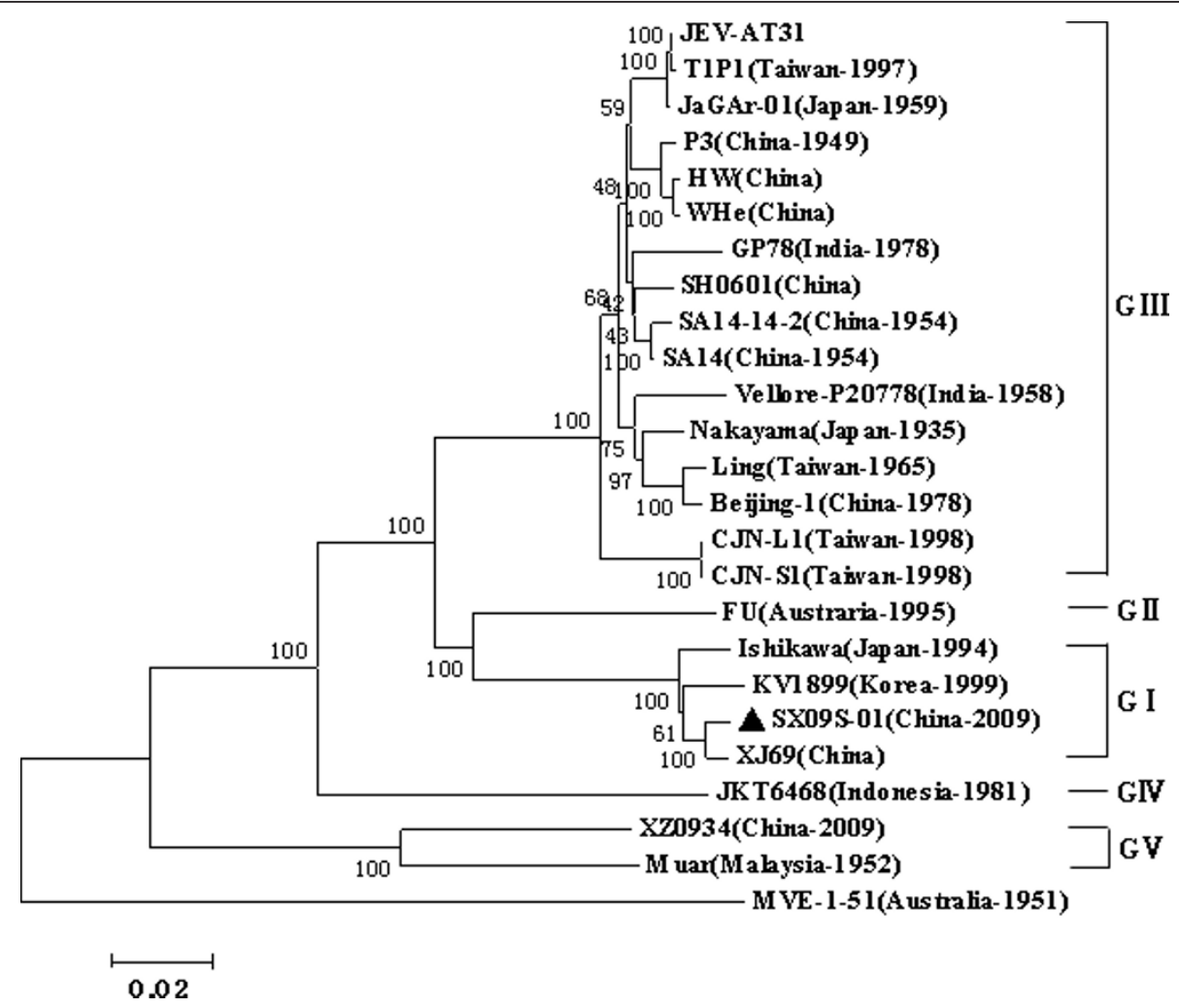

Figure 3 Phyogenetic analysis of JEV strains based on the full-length genome. The multiple sequence alignments were obtained by Mega4.1 software, and tree was constructed by the neighbor-joining method. Newly isolated strain, SX09S-01, was indicated by black triangle marker. Scale bar indicates number of nucleotide substitutions per site. Bootstrap confidence limits are shown at each node. The full-length genome sequence of the Murray Valley encephalitis virus (MEV) was used as an outgroup.

different geographic regions at different time periods, a 13-nucleotide region that immediately followed the ORF stop codon was deleted in the genome of SX09S-01 (Figure 2). Similar deletions in this region were also observed in FU [1], K94P05 [22], Ishikawa strains (GenBank accession number AB051292), and Ling strain [23]. RNA secondary structure doesn't exist in this region by computational analyses [24,25]. Ta and Vrati [26] reported that a 60-nucleotide variable region immediately downstream of the ORF stop codon in JEV genome is not required for viral replication. However, it has recently been suggested that this variable region in the 3'-NTR may play an important role on the rate of viral RNA replication [22,27,28], but it still needs further clarification.

JEV E protein forms the viral spikes on the surface and has important biological functions related to virulence and viral host tropism. In this study, we compared the eight critical amino acids in E protein that are closely related with the neurovirulence of JEV with other virulent and attenuated vaccine SA14-14-2 strains and found that SX09S-01 strain has these typical characters of high virulent strain (Table 2) and displays high neurovirulence and low neuroinvasiveness in mice (Additional file 3). These results indicated that neuroinvasiveness of JEV may not have closely relations with the eight amino acids in the E protein and some other gene(s) contributed in part of the level of neuroinvasiveness. Nerome [19] reported that Sw/Mie/40/2004 is a high neurovirulent and neuroinvasive JEV and there were no amino acids differences in the E protein between Sw/Mie/40/2004 and other low neuroinasiveness strains. In addition, we also found that there was a censuses motif Arg-Gly-Asp (RGD) in the C-terminal of E protein. It has confirmed that protein contained RGD motif can interact with cellular integrins, such as VP1 protein of FMDV [29]. It is not known if JEV E protein interacts with intergrins for virus entry.

JEV can be divided into four genotypes based on a 240nucleotide highly variable sequence of prM gene [9,30-32]. However, it results in unreliable information when short sequences $(<300 \mathrm{nt})$ were used in phylogenetic analyses of flaviviruses [33]. In recent years, full-length genome and $\mathrm{E}$ gene have also been used to establish phylogenetic trees for JEV [8,34-39] and JEV can be divided into five genotypes $[7,12,40]$. JEV E protein plays important roles in both induction of protective immune responses and in the biology of the virus $[41,42]$. In order to analyze the evolution of JEV in China, sequence information of JEV strains, 


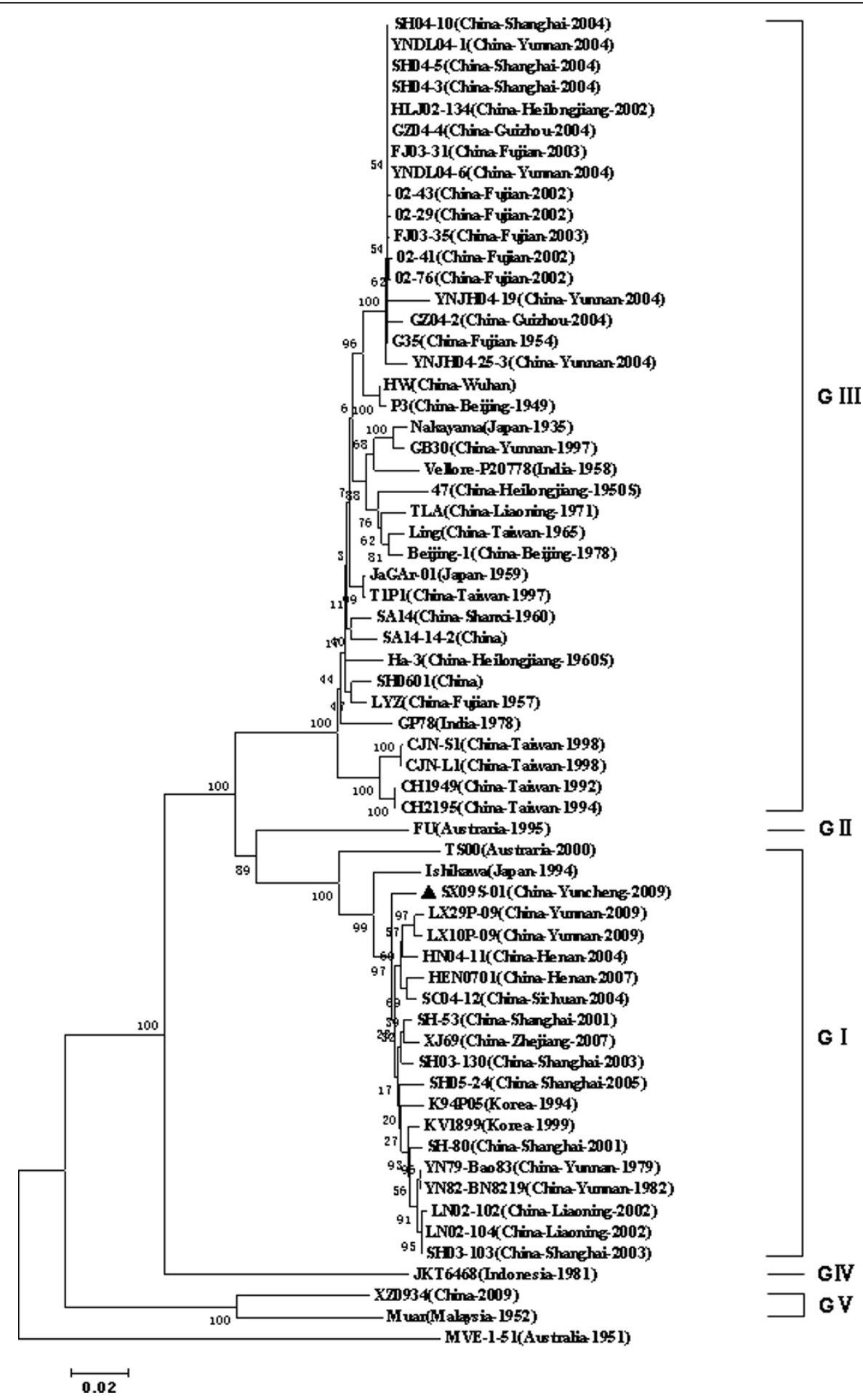

Figure 4 Phylogentic tree was constructed by the neighbour-joining method based on the E genes of JEV strains mostly selected from different geographic regions in China at different time periods, where available in Genbank listed in additional file 1.

Phylogenetic groupings corresponding to the genotyping classification are indicated from Gl to GV. Newly isolated strain is indicated with black triangle marker. The scale at the bottom of the tree indicates the number of nucleotide substitutions per site. Murray Valley encephalitis virus

(MEV) was used as an outgroup. 
originated from mainland China, were collected and phylogenetic trees were constructed on basis of the 24 fulllength genomes or $62 \mathrm{E}$ genes. Phylogenetic trees based on the full-length genomes or $\mathrm{E}$ genes provided similar topology (Figure 3, 4). JEV strains revealed five distinct phylogenetic groupings, reflecting broad geographical and temporal relationships. In China, JEV isolates are divided into three genotypes, GI, GIII and GV recently reported by Li MH et al [7]. GI strain was firstly isolated in 1979, whilst GIII strains have been isolated since the 1940s. Before the 1980s, GIII JEV was predominant in China. After 2000, there were more and more GIII JEV strains isolated and there is tendency that major genotype of JEV isolates changes from GIII to GI . In Japan, major genotype of JEV isolates had shifted from GIII to GI [19] and this phenomena were also found in Korea[39] and in Vietnam[43]. In mainland China, current vaccines used in human and pigs are inactivated or attenuated vaccines that both made up of the GIII JEV and it needs to investigate whether the same genotype shift will occur under the selected pressure of JEV vaccines.

In summary, here we have isolated GI JEV SX09S-01 strain from swine in Yuncheng in 2009. Its completed genome was sequenced and molecular characterization was analysized on the level of nucleotide and amino acid. Phyogenetic trees based on the full-length genome and $\mathrm{E}$ gene indicate that SX09S-01 strain is most closely related to the XJ69 strain. Future study should be aimed to investigate the efficacy of current vaccines against the SX09S-01 strain and other Chinese GI JEV strains and control the JE of pigs in order to prevent human JE.

\section{Additional material}

Additional file 1: Sources of the JEV strains used in the phylogenetic analysis in this study. a Information unavailable. b Strain names labeled with bold world represent the full-length genome sequences available in GenBank. c Sequences used in the present study.

Additional file 2: Comparisons of the complete genomic sequence of the SX09S-01 strain with the sequences of 23 JEV strains available in GenBank. 1-24: SX09S-01, Ishikawa, KV1899, XJ69, FU, CJNL1, CJN-S1, GP78, HW, JaGAr 01, JEV-AT31, Ling, Nakayama, P3, SA14-14-2, SA14, SH0601, T1P1, Vellore P20778, WHe, Beijing-1, JKT6468, Muar, XZ0934. The percent nucleotide sequence identities of the complete genomes are presented at the upper right. The percent amino acid sequence identities of the complete genomes are shown in the lower left. The percentage of SX09S-01 sequence identities are indicated in boldface type.

Additional file 3: Comparative analysis of neurovirulence and neuroinvasiveness of the newly swine isolate and P3 strain. a Examined by intracerebral inoculation with $30 \mu \mathrm{l}$. b Examined by intraperitoneal inoculation with $500 \mu$ l.

\section{Acknowledgements}

We really thank Dr. Yanfang Sun for immunohistochemistry experiment and Dr Shengbo Cao for good suggestions on this study. We also thank Professor Zhengfan Fu, University of Georgia, USA, for language editing. This work is supported by "973" projects (2011CB504704,2010CB530103), the National Natural Science Foundation of China (30800817, 31170144, 31121004) and Huazhong Agricultural University Scientific \& Technological Self-innovation Foundation (2009SC006).

\section{Author details}

${ }^{1}$ State Key Laboratory of Agricultural Microbiology, Huazhong Agricultural University, Wuhan city 430070, Hubei Province, P. R. China. 'Laboratory of Animal Virology, College of Veterinary Medicine, Huazhong Agricultural University, Wuhan city 430070, Hubei Province, P. R. China.

\section{Authors' contributions}

QSC, XML, QYZ carried out most of the experiments and drafted the manuscript. HCC and PQ critically revised the manuscript and the experiment design. DDW helped with the experiment. All of the authors read and approved the final version of the manuscript.

\section{Conflicts of interests}

The authors declare that they have no competing interests.

Received: 17 June 2011 Accepted: 14 October 2011

Published: 14 October 2011

\section{References}

1. Williams DT, Wang LF, Daniels PW, Mackenzie JS: Molecular characterization of the first Australian isolate of Japanese encephalitis virus, the FU strain. J Gen Virol 2000, 81:2471-2480.

2. Ghosh D, Basu A: Japanese Encephalitis-Pathological and Clinical Perspective. PLoS Negl Trop Dis 2009, 3:e437.

3. Centers for Disease Control and Prevention: Japanese Encephalitis in Two Children — United States, 2010. MMWR Morb Mortal Wkly Rep 2011, 60:276-278.

4. Saxena SK: Japanese encephalitis: perspectives and new developments. Future Neurol 2008, 3:515-521.

5. Gao XY, Nasci R, Liang GD: The Neglected Arboviral Infections in Mainland China. PloS Negl Trop Dis 2010, 4:e624.

6. Vaughn DW, Hoke CH Jr: The epidemiology of Japaneseencephalitis: prospects for prevention. Epidemiol Rev 1992, 14:197-221.

7. Li MH, Fu SH, Chen WX, Wang HY, Guo YH, Liu QY, Li YX, Luo HM, Da W Duo Ji DZ, Ye XM, Liang GD: Genotype v Japanese encephalitis virus is emerging. PLoS Negl Trop Dis 2011, 5:e1231.

8. Zhang JS, Zhao QM, Guo XF, Zuo SQ, Cheng JX, Jia N, Wu C, Dai PF, Zhao JY: Isolation and Genetic Characteristics of Human Genotype 1 Japanese Encephalitis Virus, China, 2009. Plos One 2011 6:e16418.

9. Wang LH, Fu SH, Wang HY: Japanese Encephalitis Outbreak, Yuncheng, China, 2006. Emerg Infect Dis 2007, 13:1123-1125.

10. Chen WR, Rico-Hesse R, Tesh RB: A new genotype of Japanese encephalitis virus from Indonesia. Am J Trop Med Hyg 1992, 47:61-69.

11. Weaver SC, Reisen WK: Present and future arboviral threats. Antiviral Reaearch 2010, 85:328-345.

12. Salomon T, Ni H, Beasley DW, Ekkelenkamp M, Cardosa MJ, Barrett ADT: Origin and evolution of Japanese encephalitis virus in southeast Asia. J Virol 2003, 77:3091-3098.

13. Goto A, Hayasaka D, Yoshii K, Mizutani T, Kariwa H, Takashima I: A BHK-21 cell culture-adapted tick-borne encephalitis virus mutant is attenuated for neuroinvasiveness. Vaccine 2003, 21:4043-4051.

14. Li XM, Liu RF, Tan HJ, Jin ML, Chen HC, Qian P: Induction of protective immunity in swine by immunization with live attenuated recombinant pseudorabies virus expressing the capsid precursor encoding regions of Foot and Mouth Disease virus. Vaccine 2008, 26:2714-2722.

15. Chung YJ, Nam JH, Ban SJ, Cho HW: Antigenic and genetic analysis of Japanese encephalitis virus isolated from Korea. Am J Trop Med Hyg 1996, 55:91-97.

16. McMinn PC: The molecular basis of virulence of the encephalitogenic flaviviruses. J Gen Virol 1997, 78:2711-2722

17. Pan XL, Liu H, Wang HY, Fu SH, Liu HZ, Zhang HL, Li MH, Gao XY, Wang JL, Sun XH, Lu XJ, Zhai YG, Meng WS, He Y, Wang HQ, Han N, Wei B, Wu YG, Feng Y, Yang DJ, Wang LH, Tang Q, Xia G, Kurane I, Rayner S, Liang GD: Emergence of genotype I of Japanese encephalitis virus as the dominant genotype in Asia. J Virol 2011, 85:9847-9853. 
18. Tang WF, Ogawa M, Eshita Y, Aono H, Makino Y: Molecular evolution of Japanese encephalitis virus isolates from swine in Oita, Japan during 1980-2009. Infect Genet Evol 2010, 10:329-336.

19. Nerome R, Tajima S, Takasaki T, Yoshida T, Kotaki A, Lim CK, Ito M, Sugiyama A, Yamauchi A, Yano T, Kameyama T, Morishita I, Kuwayama M, Ogawa T, Sahara K, Ikegaya A, Kanda M, Hosoya Y, Itokazu K, Onishi H, Chiya S, Yoshida Y, Tabei Y, Katsuki K, Tabata K, Harada S, Kurane I: Molecular epidemiological analyses of Japanese encephalitis virus isolates from swine in Japan from 2002 to 2004. J Gen Virol 2007, 88:2762-2768.

20. Zheng H, Zhang JW, YU SS: Isolation of Japanese encephalitis virus from swine and analyses of its E protein. Chinese Journal of Veterinary Science and Technology 2009, 39:476-482.

21. Wang $W H$, Zhang YM, Xu XG, Xing FS, Tang QH: Cloning and sequence analysis of the full-length genome of Japanese encephalitis virus strain SXBJ07 isolated from swine. Agricultural Sciences in China 2009, 8:1392-1402

22. Nam JH, Chae SL, Won SY, Kim EJ, Yoon KS, Kim Bl, Jeong YS, Cho HW: Short report: genetic heterogeneity of Japanese encephalitis virus assessed via analysis of the full-length genome sequence of a Korean isolate. Am J Trop Med Hyg 2001, 65:388-392.

23. Jan $L R$, Chen KL, Lu CF, WU YC, Horng CB: Complete nucleotide sequence of the genome of Japanese encephalitis virus ling strain: the presence of a 25-nucleotide deletion in the 3'-nontranslated region. Am J Trop Med Hyg 1996, 55:603-609.

24. Proutski V, Gould EA, Holmes EC: Secondary structure of the $3^{\prime}$ untranslated region of flaviviruses: similarities and differences. Nucleic Acids Res 1997, 25:1194-1202.

25. Rauscher S, Flamm C, Mandl CW, Heinz FX, Stadler PF: Secondary structure of the 3'-noncoding region of flavivirus genomes: comparative analysis of base pairing probabilities. RNA 1997, 3:779-791.

26. Ta M, Vrati S: Mov34 protein from mouse brain interacts with the $3^{\prime}$ noncoding region of Japanese encephalitis virus. J Gen Virol 2000, 74:5108-5115.

27. Nam JH, Chae SL, Park SH, Jeong YS, Joo MS, Kang CY, Cho HW: High level of sequence variation in the $3^{\prime}$ noncoding region of Japanese encephalitis viruses isolated in Korea. Virus Genes 2002, 24:21-27.

28. Silva PA, Molenkamp R, Dalebout TJ, Charlier N, Neyts JH, Spaan WJ, Bredenbeek PJ: Conservation of the pentanucleotide motif at the top of the yellow fever virus 17D $3^{\prime}$ stem-loop structure is not required for replication. J Gen Virol 2007, 88:1738-1747.

29. Ruiz-Sáenz J, Goez Y, Tabares W, López-Herrera A: Cellular receptors for foot and mouth disease virus. Intervirol 2009, 52:201-212.

30. Chen WR, Tesh RB, Rico-Hesse R: Genetic variation of Japanese encephalitis virus in nature. J Gen Virol 1990, 71:2915-2922.

31. Huong VTQ, Ha DQ, Deubel V: Genetic study of Japanese encephalitis viruses from Vietnam. Am J Trop Med Hyg 1993, 49:538-544.

32. Ali A, Igarashi A: Antigenic and genetic variations among Japanese encephalitis virus strains belonging to genotype 1. Microbiol Immunol 1997, 41:241-252.

33. Kuno G, Chang GJJ, Tsuchiya KR, Karabatsos N, Cropp CB: Phylogeny of the genus Flavivirus. J Virol 1998, 72:73-83.

34. Ni H, Barrett ADT: Nucleotide and deduced amino acid sequence of the structural protein genes of Japanese encephalitis viruses from different geographical locations. J Gen Virol 1995, 76:401-407.

35. Paranjpe S, Banerjee K: Phylogenetic analysis of the envelope gene of Japanese encephalitis virus. Virus Res 1996, 42:107-117.

36. Wu S, Lian W, Hsu L, Wu Y, Liau M: Antigenic characterization of nine wild-type Taiwanese isolates of Japanese encephalitis virus as compared with two vaccine strains. Virus Res 1998, 55:83-91.

37. Mangada MNM, Takegami T: Molecular characterization of the Japanese encephalitis virus representative immunotype strain JaGAr01. Virus Res 1999, 59:101-112.

38. Yun SI, Kim SY, Choi WY, Nam JH, Ju YR, Park KY, Cho HW, Lee YM: Molecular characterization of the full-length genome of the Japanese encephalitis viral strain K87P39. Virus Res 2003, 96:129-140.

39. Yang DT, Kim BH, Kweon CH, Kwon JH, Lim SI, Han HR: Molecular characterization of full-length genome of Japanese encephalitis virus (KV1899) isolated from pigs in Korea. J Vet Sci 2004, 5:197-205.

40. Mohammed MA, Galbraith SE, Radford AD, Dove W, Takasaki T, Kurane I, Solomon T: Molecular phylogenetic and evolutionary analyses of Muar strain of Japanese encephalitis virus reveal it is the missing fifth genotype. Infect Genet Evol 2011, 11:855-862.

41. Fan JM, Luo J, Zhang GP, Chen L, Teng M, Yang MF, Wang L, Wang CQ: Identification and characterization of Japanese encephalitis virus envelope protein gene from swine. Lett Appl Microbiol 2010, 51:11-17.

42. Nam JH, Chung YJ, Ban SJ, Kim EJ, Park YK, Cho HW: Envelope gene sequence variation among Japanese encephalitis viruses isolated in Korea. Acta Virol 1996, 40:303-309.

43. Nga PT, Del Carmen Parquet M, Cuong VD, Ma SP, Hasebe F, Inoue S, Makino Y, Takagi M, Nam VS, Morita K: Shift in Japanese encephalitis virus (JEV) genotype circulating in northern Vietnam: implications for frequent introductions of JEV from Southeast Asia to East Asia. J Gen Virol 2004, 85:1625-1631.

\section{doi:10.1186/1743-422X-8-472}

Cite this article as: Cao et al:: Isolation and molecular characterization of genotype 1 Japanese encephalitis virus, SX09S-01, from pigs in China. Virology Journal 2011 8:472.

\section{Submit your next manuscript to BioMed Central and take full advantage of:}

- Convenient online submission

- Thorough peer review

- No space constraints or color figure charges

- Immediate publication on acceptance

- Inclusion in PubMed, CAS, Scopus and Google Scholar

- Research which is freely available for redistribution

Submit your manuscript at www.biomedcentral.com/submit
Biomed Central 